\title{
Everyday Annoyances and Stress Resilience: Stress Factors of Helping Professions
}

\author{
Petia Genkova \\ University of Applied Science, Osnabrueck, Germany
}

\begin{abstract}
The study at hand focuses the interdependencies between stress incidents and strategies of stress-coping in relation with well-being in helping professions. Furthermore, the scarce areas and the proband's strategies of health behavior, comparing helping and other vocational groups, are investigated. The sample consist of teachers, bank employees, employees of marketing agencies, employees coming from the machine construction industry, as well as nurses, psychotherapists and physicians. The results show that everyday annoyances and problem-oriented stress-coping indeed affect well-being.
\end{abstract}

Keywords: stress, well-being, everyday annoyances, critical incidents, helping professions

\section{Introduction and Theoretical Basics}

In the last decades, there were numerous investigations conducted proving the health-damaging effects of work strain. The actual developments of the labor market lead to other kinds of work strain that have ambivalent effects on physical and psychic health, without entailing clear implications for action. According to estimates, the share of vocational induced illnesses is still at approximately $20 \%-30 \%$ of the overall volume of inabilities to work (Richter, Buruck, Nebel, \& Wolf, 2011). Today's everyday work is characterized by steady changes and herewith connected increasing demands. This usually counts for helping professions, meaning physicians, nurses, etc.. Today, burnout-research is advanced and is strongly connected to work-life-balance and health psychology.

In reaction-related approaches, the term stress means physical, psychical or behavioral adaptation-reactions that occur independent of the causing stimulus (Nitsch, 1981). Regarding situation-related concepts, not individuals and their reactions on stimuli, but these stimuli or stressors themselves are in the foreground. To the most important situation-related stress concepts belongs the theory of critical life incidents, as represented by Holmes and Rahe (1967), amongst others. According to this theory, critical life incidents are connected to high strain that require a certain amount of social readjustment and that can cause psychic disorders or physical illness (Jerusalem, 1990). Regarding SRRS (the Social Readjustment Rating Scale), Holmes and Rahe (1967) developed a method for the assessment of the inherent stress-level of such life incidents. The stress-level of a life incident on the SRRS is indicated with the help of so-called LCUs (life-change units). Based on the accumulation of these values, the amount of stress can be indicated that an individual experiences in his/her life course. New research findings show that stress is no more a one-sided construct, but rather is a mutuallyongoing process between a person and his/her environment (Jerusalem, 1990).

Petia Genkova, Ph.D., professor, Chair in Department of Business Psychology, University of Applied Science. 
Stressors condition in dependence of evaluation and coping processes the psychical and physical health of employees. This process is influenced by resources. But also person-related characteristics influence the evaluation of stress and stress-coping. Important personal resources are vocational competences, self-worth, self-efficacy, control-cognitions, sense of coherence, hardiness, optimism and creation of meaning (Zapf \& Semmer, 2004).

\section{Question, Hypotheses, and Sample Description}

The central question of this investigation deals with the interdependencies between stress incidents and strategies of stress-coping in relation with well-being in helping professions. Additionally, for the further generation of hypotheses, the scarce areas and the proband's strategies of health behavior, comparing helping and other vocational groups, shall be detected. The "Fragebogenzur Erfassung des allgemeinen Wohlbefindens (questionnaire for the assessment of general well-being)" (FEW) of Bongartz (2000) as well as the "Landauer Fragebogenzum Arbeitsstil (Landau questionnaire for the assessment of work style)" (LFA) were used. The also in the questionnaire used "Skalazur Erfassung des Bewältigungsverhaltens" (SEBV, Ferring \& Filipp, 1989 ) is a German Version of the developed English "Ways of Coping Checklist". The sample consists of 645 persons, of whom 268 are men and 377 are women (age span: 18-53 years; $M W=37.61$ ). The following vocational groups were consulted: teachers (112); bank employees, employees of marketing agencies, employees coming from the machine construction industry (124); as well as nurses, psychotherapists, and physicians (134).

Two hypotheses were tested: Hypothesis 1: The critical incidents are a stronger predictor for the negative well-being than everyday annoyances are. Hypothesis 2: Regarding helping professions, the emotion-oriented strategies of stress-coping are stronger predictors for well-being than problem-oriented strategies are.

\section{Results and Discussion}

To test for the first hypothesis, a regression analysis was conducted, in which well-being was used as a dependent variable. Based on this, a structural equation model could be set up. The critical incidents $(\beta=$ $\left.-0.103^{* * *}\right)$ and the everyday annoyances $\left(\beta=-0.365^{* * *}\right)$ significantly predict well-being $\left(\Delta R^{2}=0.28\right)$. In contrast to the notion that critical incidents stronger affect well-being, the results show, that everyday annoyances clearly much stronger affect well-being. This counts for all vocational groups. A graphical presentation of the results can be seen in Figure 1.

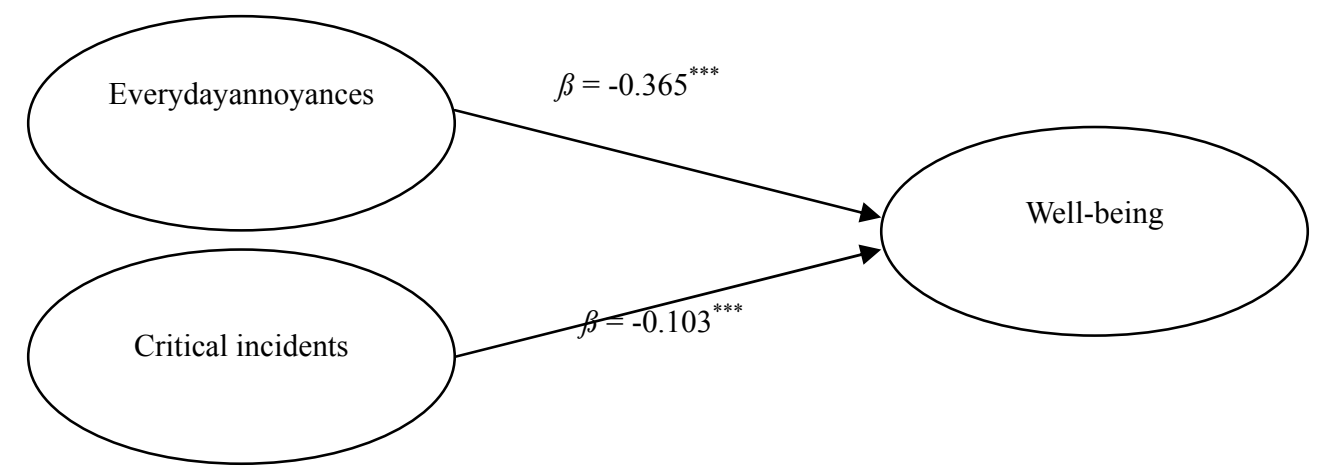

Figure 1. Graphical presentation of the regression analysis for the testing of hypothesis 1. 
To test for the relationship by comparing groups (helping professions and other vocational groups), a structural equation model was analyzed, whereby the analysis for the whole sample was conducted first. The fits of the model show $\left(\mathrm{Chi}^{2}=1.237, d f=5, p=0.266\right.$; REMSEA $=0.053$, Lo90.000 Hi90.303, CFI $=0.978$, $\mathrm{CMIN} / d f=15.775)$, that it was confirmed. For helping professions, one would assume that the critical incidents and the steady fight with extreme situations and sorrow play a stronger role for well-being. This is disproved by the results, because obviously, the employees of helping professions adapted to their "usual" stress and are only tattered by additional stress factors $\left(\mathrm{Chi}^{2}=8.373 d f=5 ; p=0.137 ; \mathrm{CMIN} / d f=1.675 ; \mathrm{CFI}=0.964 ; \mathrm{RMSEA}=\right.$ 0.099 (Lo90.000; Hi90.212)). This also counts for the other professions $\left(\mathrm{Chi}^{2}=10.626 d f=5 ; p=0.059\right.$; $\mathrm{CMIN} / d f=0.125 ; \mathrm{CFI}=0.894 ; \mathrm{RMSEA}=0.128($ Lo90.000; Hi90.235) $)$.

To verify the second hypothesis, regression analyses were calculated again. For the group of helping professions, one realizes that problem-oriented strategies of stress-coping $\left(\beta=0.321^{* * *}\right)$ much stronger predict well-being than emotion-centralized strategies of stress-coping do $\left(\beta=0.201^{* *}, \Delta R^{2}=0.143\right)$. Thus, this hypothesis is disproved for the group of helping professions.

Here, similar assumptions could be made in a way that the implicit strains of helping professions are regarded as being "normal" and count as to be coped tasks. Based on the implications of stress theory, this finding would seem to be conform with the theoretical approaches due to through the adaptation to an everyday stress situation, stress-coping is practiced. In this way, the for other professions "unusual" strains and demands are regarded as being normal and are "compensated" with the help of routine.

In this study, no personality-relevant variables were considered, that could give hints for the question, whether emotional strains and their coping are related to this or really with tasks of helping professions. However, the findings are a clear hint for the fact, that everyday annoyances and problem-oriented stress-coping much stronger affect well-being than assumed. A more complex model, in which well-being is the dependent variable, the strategies of coping are the moderators and the critical incidents and everyday annoyances are the independent variables, could not have been confirmed during further testing.

If one follows the psychological approach, stress is understood as a dynamic interdependency between the individual and his/her work environment (Cox, Oliver, Rial-Gonzalez, Tomas, Griffiths, \& Thompson, 2006). Crucial for the defense of the permanent effects of stress is self-reflection and self-ability to judge, to be able to react to early warning signals (Cassens, 2003).

It is important to keep the health state of people, which is significantly coined by work and life conditions, constant and nurse it due to only in this way, motivation and willingness to perform are maintained and organizational success is secured.

\section{References}

Bongartz, N. (2000). Wohlbefinden als Gesundheitsparameter. Theorie und treatmentorientierteDiagnostik (Well-being as an indicator of health: Theory and treatment-oriented diagnostic). Landau: Verlag Empirische Pädagogik.

Cassens, M. (2003). Work-Life-Balance. Wie Sie Berufs- und Privatleben in Einklang bringen (Work-Life-Balance. How you integrate the vocational and private life area). (Executive Summary) München: dtv.

Cox, T., Oliver, A., Rial-Gonzalez, E., Tomas, J. M., Griffiths, A., \& Thompson, L. (2006). The development of a Spanish language version of the worn out scale of the General Well-Being Questionnaire (GWBQ). Spanish Journal of Psychology, 9(1), 94-102.

Ferring, D., \& Filipp, S. H. (1989). BewältigungkritischerLebensereignisse: ErsteErfahrungenmiteinerdeutschsprachigen Version der "Ways of Coping Checklist" (Coping of critical life incidents: First experiences with the German version of the "Ways of Coping Checklist"). Zeitschrift für Differentielle und Diagnostische Psychologie (Journal of Differential and Diagnostic Psychology), 10, 189-199. 
Hobfoll, S. E. (2001). The influence of culture, community, and the nested-self in the stress process: Advancing conservation of resources theory. Applied Psychology: An International Review, 50(3), 337-421.

Holmes, T., \& Rahe, R. (1967). The Social Readjustment Rating Scale (electronic version). Journal of Psychosomatic Research, $11,213-218$.

Jerusalem, M. (1990). PersönlicheRessourcen, Vulnerabilität und Streßerleben (Personal resources, vulnerability and experience of stress). Göttingen: Hogrefe.

Lazarus, R. S., \& Folkman, S. (1984). Stress, appraisal, and coping. New York: Springer.

Nitsch, J. (1981). Stress. Theorien, Untersuchungen, Maßnahmen (Stress. Theories, investigations, measures). Bern: Huber.

Richter, P., Buruck, G., Nebel, W., \& Wolf, S. (2011). Arbeit und Gesundheit. Risiken, Ressourcen und Gestaltung (Work andhealth. Risks, resourcesanddesign). In E. Bamberg, A. M. Metz, \& A. Ducki (Eds.), Handbuch Gesundheitsförderung und Gesundheitsmanagement in der Arbeitswelt (Handbook ofhealth-promotion andHealth Management in theworkingworld) (pp. 25-61). Göttingen: Hogrefe.

Zapf, D., \& Semmer, N. K. (2004). Stress und Gesundheit in Organisationen (Stress andhealth in organizations). In H. Schuler (Ed.), Organisationspsychologie—Grundlagen und Personalpsychologie (Organisational psychology—Basics and personnel psychology) (pp. 1007-1112). Göttingen: Hogrefe. 